\title{
PKM. Peningkatan Usaha Jamu Saritoga Ukm "Prayogo" dan Karang Taruna "Bhakti" Dusun Lopawon Desa Kebobang Wonosari Kabupaten Malang
}

\author{
Ike Kusdyah Rachmawati ${ }^{1}$, Any Isvandiari ${ }^{2}$, Titania Dwi Andini ${ }^{3}$,Syarif Hidayatullah ${ }^{4}$ \\ $1,2,3$ Sekolah Tinggi Ilmu Ekonomi Asia Malang, ${ }^{4}$ Universitas Merdeka Malang \\ e-mail:syarif_ok@yahoo.com
}

\begin{abstract}
Abstrak
Untuk meningkatkan produksi jamu instan herbal salah satu aspek yang diperlukan adalah ketersediaan bahan dan peralatan yang dapat menunjang peningkatan proses produksi .Untuk itu pembuatan jamu herbal instan berbasis bahan rimpang lokal melalui bantuan peralatan modern, menjadi solusi yang perlu diupayakan. Ketersediaan bahan baku lokal dan dukungan peralatan modern akan mendorong produktifitas jamu instan herbal meningkat, karena biaya produksi makin efisien. Peningkatan produksi jamu herbal instan akan menjamin meningkatnya ketersediaan bahan baku siap jual bagi ukm Prayogo dan giat memproduksi produk olahan jamu lainnya. Upaya meningkatkan produksi dan omset penjualan perlu ditopang dengan perbaikan manajemen produksi dan sarana pendukung produksi. Serta penataan manajemen dan sistem pemasaran dengan media online. Tujuan pelaksanaan Pengabdian Pada Masyarakat ini untuk meningkatkan produksi baik kuantitas dan kualitas, meningkatkan motivasi dalam berwirausaha bagi mitra, pemahaman dan ketrampilan mitra, omset penjualan dari masing masing mitra, ketentraman/kesehatan masyarakat, menghasilkan produk jamu instan herbal serta varian jenis lainnya. Pelaksanaan kegiatan pada UKM Prayogo, berupa bantuan Peralatan yang digunakan berupa mesin pengekstrak jahe dengan kapasitas produksi 20-30 liter. Pelaksanaan pada Kelompok Karang Taruna "Bhakti" dengan peningkatan dan sosialisasi motivasi berwirausaha, meningkatkan ketrampilan, Tim Pengabdian Pada Masyarakat melakukan pendampingan dengan praktek pembuatan jamu instan herbal, pembuatan media promosi dengan media online. Luaran kegiatan pengabdian kepada masyarakat ini adalah berupa: (1) Bantuan peralatan mesin pengekstrak jahe instan; (2) diversifikasi produk olahan baru berupa aneka jamu selain jahe (3) publikasi media massa (4) draf Publikasi Ilmiah
\end{abstract}

Kata Kunci : alat /mesin pengekstrak jahe; jamu instan; karangtaruna

\begin{abstract}
To increase the production of herbal instant herbal medicine is needed is the availability of materials and equipment that can support the improvement of the production process. The availability of local raw materials and the support of modern equipment will encourage the productivity of herbal instant herbs to increase, because production costs are more efficient. The increase in the production of instant herbal medicine will guarantee the increasing availability of ready-to-sell raw materials for Prayogo SMEs and actively produce other processed herbal products. Efforts to increase production and sales turnover need to be supported by improvements in production management and production support facilities. The results of mentoring in the implementation of Community Service are to increase production both quantity and quality, motivation in entrepreneurship for partners, partner understanding and skills, sales turnover of each partner, improve public health, produce herbal instant herbal products and other types of variants.Implementation of activities on. Prayogo SMEs, in the form of assistance Equipment used in the form of ginger extractor with a production capacity of 20-30 liters. The implementation with the improvement and socialization of entrepreneurial motivation, improving skills, Community Service Team assisted with the practice of making herbal diamond herbal medicine, making media promotions with online media. The output of community service activities are in the form of: (1) Assistance for instant ginger extraction equipment; (2) diversification of new processed products in the form of various herbs in addition to ginger (3) mass media publications (4) draft Scientific Publication.
\end{abstract}

Keywords: ginger extraction machine; instant herbal; SMEs; youth organization 


\section{PENDAHULUAN}

Kecamatan Wonosari terletak di Kabupaten Malang memiliki luas $4500 \mathrm{Ha}$, dengan jumlah penduduk sebesar 700.000 jiwa merupakan bagian dari Kabupaten Malang dengan jarak $\pm 30 \mathrm{Km}$ dari Kota Malang, dengan temperatur udara rata-rata $10-30^{\circ} \mathrm{C}$ dan berada pada ketinggian 500-2000 $\mathrm{m}$ dpl. Kecamatan Wonosari berada pada $-8.006770^{\circ}$ Lintang Utara, $-8.040742^{\circ}$ Lintang Selatan, $112.494278^{\circ}$ Bujur Timur, dan $112.463581^{\circ}$ Bujur barat. Berdasarkan topografi, keadaan atau kondisi tanah di Kecamatan Wonosari sangatlah subur sehingga sangat cocok untuk pertanian maupun perkebunan, dari sektor perkebunan dihasilkan cengkeh dan kopi, dari sektor pertanian dihasilkan palawija ( Jagung, Ubi kayu, Ubi jalar ), pisang serta tanaman rimpang (hemaprodite).Kecamatan Wonosari merupakan pemekaran dari Desa Kebobang Kecamatan Ngajum sehingga pada tahun 1986 menjadi Desa Wonosari ${ }^{1}$.

Kegiatan masyarakat rata-rata bercocok taman, ada sebagian masyarakat yang berusaha mengembangkan kegiatan pengolahan hasil pertanian menjadi aneka jamu². Salah satu UKM yang melaksanakan kegiatan tersebut adalah UKM Prayogo sejak 2005 memiliki usaha aneka minuman jamu sari toga. Produk ini baru dipasarkan di sekitar kecamatan Wonosari. Selain hal tersebut, Desa Kebobang juga terdapat Karang Taruna yang memiliki tujuan untuk pengembangan desa dan masyarakat desa. Atas dasar tesebut maka karang taruna tersebut dinamakan "Bhakti". Karang Taruna Bhakti Dusun Lopawon Desa Kebobang memiliki visi untuk mewujudkan kemandirian masyarakat Pedesaan khususnya mendayagunakan potensi generasi muda Karang taruna di bidang kewirausahaan.

Berdasarkan latar belakang di atas, kegiatan ini secara nyata dapat diwujudkan dalam pendekatan pembangunan ekonomi kemasyarakatan.Tujuan dari kegiatan tersebu adalah:
1. Pengoptimalan pengembangan masyarakat Dusun Lopawon melalui pendekatan pemberdayaan masyarakat untuk dapat meraih peluang usaha sekaligus diversifikasi produk melalui prasarana dan sarana ${ }^{3}$

2. Meningkatkan partisipasi generasi muda melalui karang taruna dengan sinergi yang positif dengan UKM untuk peningkatan mitra usaha dan pengelolaan serta peningkatan ekonomi

3. Meningkatnya pengetahuan dan ketrampilan dalam berwirausaha pada mitra

\section{SUMBER INSPIRASI}

Permasalahan utama/pokok dalam Program PKM ini berdasarkan kebutuhan prioritas mitra 1 (UKM Prayogo) dan mitra 2 (karang taruna Bhakti). Dimana, Persoalan atau kebutuhan pokok yang dihadapi Oleh mitra UKM Prayogo, dan Karang Taruna "Bhakti" dalam penerapan Ipteks bagi Masyarakat (IbM) ini adalah UKM Prayogo : a) Aspek Produksi, Jumlah produksi yang dihasilkan masih sedikit \& terbatas, Produk yang dibuat selama ini hanya jahe instan, b) Aspek sistem packaging dan label produk, sistem packing atau kemasannya belum memenuhi standart kemasan c). Aspek pemasaran/produk, Tidak bisa memenuhi permintaan pasar dalam jumlah besar karena rendahnya hasil produksi akibat dari kapasitas produksi yang terbatas. d) Aspek Pemasaran, pemasaran yang masih terbatas dijual di daerah sekitar desa Kebobang dan desa Wonosari saja, e) Aspek sumberdaya manusia, skill atau kemampuan yang terbatas f). Aspek pangsa pasar, kemampuan meluaskan pemasaran yang masih lemah dan hanya melalui jalur lokal kecamatan Wonosari dan sekitarnya.g) Aspek Penguasaan teknologi, sulitnya mengubah kebiasaan masyarakat yang kurang tanggap terhadap manfaat alih fungsi Teknologi h) Aspek Pengembangan Usaha, Kurangnya motivasi untuk pengembangan bisnis .Karang Taruna "Bhakti" a) Aspek Produksi, belum memiliki pengetahuan \& 
wawasan sama sekali tentang produk pengolahan minuman jamu, b) Aspek Kewirausahaan, keterbatasan pengetahuan tentang manajemen usaha dan belum memiliki motivasi kewirausahaan, c) Aspek Manajemen Bisnis, Belum memiliki Perencanaan Bisnis (Business Plan) yang jelas sehingga target dan sasaran usaha belum memiliki arah kepada pengembangan usaha bisnis yang mantap, d) Aspek Permodalan, Lemahnya akses terhadap permodalan sehingga makin menyurutkan minat pemuda karang Taruna dalam memulai usaha.e) Aspek sumberdaya manusia, terbatasnya pengetahuan serta ketrampilan.

Berdasarkan prioritas permasalahan yang diadapi oleh mitra maka pihak PKM menberikan beberapa solusi. Berdasarkan analisis kebutuhan mitra dengan sentuhan ipteks. Solusi yang ada dalam program ini adalah : a) Peningkatan kualitas dan kuantitas produk minuman saritoga, b) Memperluas jaringan pemasaran mitra, c) Peningkatan kemampuan manajerial mitra.

Prioritas Program PKM yang disepakati bersama antara mitra dengan pengusul tentunya disesuaikan dengan kebutuhan mitra adalah sebagai berikut 1). Pengadaan sarana / alat guna menunjang proses produksi pada UKM Prayogo. Peralatan tersebut perlu diberikan untuk menunjang kelancaran operasional kegiatan UKM Prayogo. Serta Pengelolannya harus berdasarkan kesepakatan bersama. Sehingga alat tersebut sekaligus dapat digunakan untuk melatih para kader Karang Taruna sebagai proses transformasi ilmu dan ketrampilan, 2). Penyuluhan \& Pelatihan manajemen serta kewirausahaan guna meningkatkan skill motivasi usaha, pada Karang Taruna "Bhakti", 3). Pelatihan pembuatan produk baru atau diversfikasi produk guna meningkatkan perluasan usaha dan produk, pada UKM Prayogo dan Karang Taruna "Bhakti", 4).Pelatihan pembuatan blog/web untuk memperluas pasar dengan pemasaran melalui media on line pada
UKM Prayogo, 5). Pembuatan label produk yang lebih menarik dan content penulisan produk yang benar pada UKM Prayogo

\section{METODE KEGIATAN}

Pelaksanaan kegiatan ini adalah dengan menggunakan metode konsultasi, penyuluhan, pelatihan dan pendampingan. 1). Konsultasi : Dengan materi aspek produksi, pemasaran, manajemen bisnis, wirausaha dll, indikator keberhasilan dengan mengetahui secara nyata permasalahan mitra sekaligus alternatif solusi. 2). Penyuluhan : Materi motivasi \& kewirausahaan, Busniess Plan dan Website Promosi. Indikator Peningkatan kreatiitas,keuletan, ide , keberanian resko usaha , kewirausahaan kemampuan teknologi \& jaringan pemasaran. 3). Pelatihan : Dengan materi Pelatihan membuat jamu bubuk, kopi bubuk, Website \& label produk. Indikator keberhasilan Peningkatan secara nyata membuat produk olahan jamu, kopi, dendeng ubi serta membuat website \& perbaikan desain /label produk. 4). Pendampingan : Praktek membuat jamu bubuk, kopi bubuk, \&, Website \& label produk. Dengan indiator keberhasilan Mengurangi resiko kesalahan dalam praktek pembuatan jamu bubuk, kopi bubuk \& dendeng ubi, pengisian konten Website \& dan membuat label produk yang menarik.

Program ini telah dilaksanakan sejak Tahun 2018, adapun kegiatan yang dilakukan antara lain 1). Sosialisasi akan diadakan program PKM pada kelompok Karang Taruna dan UKM Prayogo, 2). Peninjauan lokasi tempat usaha pada ke 2 mitra Dimana Mitra 1 UKM Prayogo dan mitra 2 Karang Taruna Bhakti berada pada jarak \pm 500 meter, 3). Peninjauan tempat untuk kegiatan penyuluhan kepada mitra pengabdian yang berlokasi di rumah ibu Fariyani (mitra 1), 4). Identifikasi alat yang dibutuhkan oleh mitra serta wawancara awal dengan mitra, 5). Mempersiapkan kegiatan penyuluhan kepada mitra tentang produk olahan, 
6). Melaksanakan kegiatan penyuluhan program pengabdian meliputi penyuluhan untuk kewirausahaan, penyuluhan motivasi, penyuluhan untuk pemasaran WEB, pemberian alat-alat yang dibutuhkan oleh mitra yaitu Mesin Penggekstrak Jahe Instan, serta praktek produk diversifikasi

Adapun rincian kegiatan yang telah dilaksanakan sebagai berikut yakni UKM Prayogo Abinyu : Tim PKM mengumpulkan anggota UKM sasaran pada tempat pertemuan di rumah salah satu pengurus UKM untuk diberikan penjelasan tentang rencana kegiatan IbM di UKM Prayogo yang meliputi aspek (a) Bagaimana meningkatkan produksi jamu instan herbal berbahan rimpang lokal. (b). Prosedur penggunaan dan perawatan peralatan (c). Praktek penggunaan alat / mesin pendukung produksi pembuatan jamu instan (d) bagaimana menata manajemen pemasaran, (e) Bagaimana membuat promosi ia media Web Blog. Untuk meningkatkan pengetahuan khalayak sasaran mengenai materi kegiatan. menambah sarana pendukung (mesin penggiling). Kegiatan ini diikuti dengan diskusi tentang materi kegiatan yang bertujuan untuk tukar pengalaman antara tim penyuluh dengan khalayak sasaran. Khalayak sasaran diberi daftar kegiatan yang berisi tentang materi kegiatan. Untuk mendukung dan menumbuhkan meningkatkan produksi dengan label yang menarik dari produk, pengabdi berusaha membantu dengan memberikan pelatihan pembuatan label dan pemasaran.

Karang Taruna Bhakti : Tim PKM dalam melaksanakan solusi dari permasalahan Mitra 2 untuk meningkatkan motivasi berwirausaha dan memiliki ketrampilan, terkendala dengan sedikitnya jumlah anggota Karang Taruna yang belum pernah mendapatkan pelatihan kewirausahaan dan bagaimana memiliki kegiatan bisnis untuk mendapatkan penghasilan. Untuk itu tim PKM melakukan pendampingan dengan penyuluhan berwirausaha, peningkatan skill, untuk memiliki kegiatan bisnis dalam mendapatkan penghasilan dan bagaimana pemasaran produk jamu. Mengumpulkan pengurus dan anggota Karang taruna pada suatu tempat pertemuan di rumah ketua Karang Taruna untuk diberikan penjelasan tentang rencana kegiatan PKM di mitra 1 yang meliputi aspek (a) Bagaimana berwirausaha (b). Bagaimana meningkatkan skill dengan proses pembuatan jamu (c). Praktek pembuatan produk olahan jamu herbal instan. Untuk mendukung dan menumbuhkan jiwa wirausaha di kalangan Karang Taruna "Bhakti" Gunung Kawi peneliti berusaha membantu dengan memberikan pelatihan kewirausahaan.

Pembuatan Alat Mesin Pembuatan Jahe Instan. Dalam proses produksi pembuatan jamu instan yang menjadi permasalahan adalah pada proses membuat sari jahe yang cair untuk menjadi bubuk dan membutuhkan waktu selama 3 jam. Ini dilakukan dengan menambahkan gula dengan ukuran tertentu dan secara terus menerus diaduk aduk adonan diatas api yang sedang secara terus menerus hingga mendidih, ketika telah mendidih terus di aduk agar gula tidak mengkaramel atau berwarna coklat agar hasil bubuk jahe instan hasilnya bagus ${ }^{5}$.Proses ini menjadi masalah bagi UKM karena membutuhkan waktu yang lama dan secara terus-menerus mengaduk. Atas dasar tersebut, tim PKM berupaya membantu untuk pengadaan alat yang sudah di modif antara wajan dan dinamo dengan membuat tempat dan tatakan wajan untuk mempermudah dan memproses jahe cair menjadi bubuk (instan).

Pembuatan Blog UKM untuk meningkatkan promosi dalam pemasaran produk jamu instan agar dikenal masyarakat bukan hanya secara lokal namun juga secara luas perlu pemasaran secara online. Untuk membantu hal ini tim PKM membantu membuat blog awal kepada UMKM jamu untuk seterusnya di isi (posting) secara terus menerus sehingga oleh kelompok jamu : isi bisa berupa nama kelompok usaha, jenis usaha, diversifikasi usaha atau foto 
produk terbaru yang ada. Nama blog yang dibuatkan adalah http://infoabinyu.blogspot.com/

\section{KARYA UTAMA}

a. Alat/peralatan, yakni alat / mesin pemarut . Mesin ini bisa digunakan untuk memarut jahe, kelapa, ketela, ubi ,kunyit, kopi dan lain-lain.

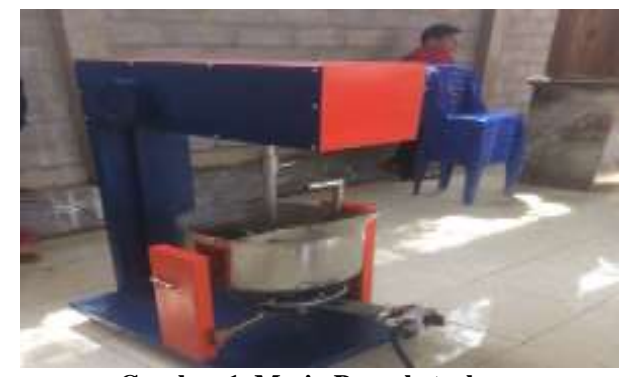

Gambar 1. Mesin Pengekstrak

b. Jasa, yaitu berupa Penyuluhan \& pelatihan yang berkelanjutan. Penyuluhan motivasi, Pelatihan kewirausahaan, pelatihan pembuatan minuman sari toga, pelatihan pembuatan web-online dan desain label produk

Outcome dari adanya pelatihan yang dilakukan bagi Karang Taruna adalah memiliki ketrampilan sebagai modal basic untuk berwirausaha, dimana produk minuman sari toga dapat dipasarkan sendiri atau dititipkan ke UKM pemberi pelatihan. Sedangkan bagi UKM Prayogo diperoleh peningkatan kapasitas produksi sekaligus dapat menyiapkan tenaga kerja muda yang lebih terampil dengan cara merekrut peserta pelatihan yang belum mampu berwirausaha.

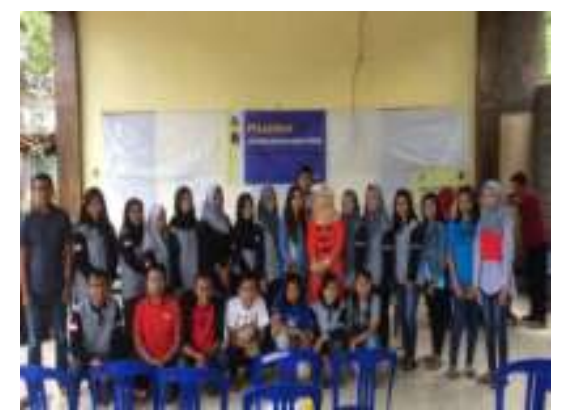

Gambar 2. Kegiatan pelatihan \& praktek kewirausahaan dengan mitra

\section{ULASAN KARYA}

Karya yang dihasilkan adalah sebagai berikut a) Alat/peralatan, yakni alat / mesin pemarut . Mesin ini bisa digunakan untuk memarut jahe, kelapa, ketela, ubi ,kunyit, kopi dan lain-lain. Dengan Spesifikasi sebagai berikut : Spesifikasi 32×30x20 cm, Material rangka : siku Besi, Material Body : Plat Besi, Material Parut ; stainless steel, Penggerak : Dinamo $1 / 2 \mathrm{hp}$, Transmisi : Pulley \& V-belt dan daya listrik 125 watt. b) Jasa, yaitu berupa Penyuluhan \& pelatihan yang berkelanjutan. Seperti : Penyuluhan motivasi, Pelatihan kewirausahaan, pelatihan pembuatan minuman sari toga, pelatihan pembuatan web-online dan desain label produk.

Pembuatan Alat Mesin Pembuatan Jahe Instan. Dalam proses produksi pembuatan jamu instan yang menjadi permasalahan adalah pada proses membuat sari jahe yang cair untuk menjadi bubuk dan membutuhkan waktu selama 3 jam. Ini dilakukan dengan menambahkan gula dengan ukuran tertentu dan secara terus menerus diaduk aduk adonan diatas api yang sedang secara terus menerus hingga mendidih, ketika telah mendidih terus di aduk agar gula tidak mengkaramel atau berwarna coklat agar hasil bubuk jahe instan hasilnya bagus. Proses ini menjadi masalah bagi UKM karena membutuhkan waktu yang lama dan secara terus-menerus mengaduk. Atas dasar tersebut, tim PKM berupaya membantu untuk pengadaan alat yang sudah di modif antara wajan dan dinamo dengan membuat tempat dan tatakan wajan untuk mempermudah dan memproses jahe cair menjadi bubuk (instan). Adapun spesifikasi mesin penekstrak jahe instan adalah sebagai berikut :

Bahan Material : Stainless steel MJIT 30

$\begin{array}{ll}\text { kapasitas } & : 20-25 \text { liter } \\ \text { listrik } & : 1200 \text { watt }\end{array}$

Material Rangka : Besi Siku

Penggerak energi : listrik

Daya/power : : $3 / 4 \mathrm{HP}$

Tenaga Listrik : 220 volt 
Frekuensi listrik : $50 \mathrm{~Hz}$

Dimensi mesin : $800 \mathrm{~mm}$ x $600 \mathrm{~mm}$ x $800 \mathrm{~mm}$

\section{Cara Kerja}

Esktrak cair jahe dimasukkan ke dalam wajan mesin pengolah. Kemudian di dipanaskan sampai mengental sedangkan pengaduk tetap di jalankan. Menjelang kental, panas dimatikan dan pengaduk tetap dijalankan .sampai mengkristal. Yang ditandai dengan pembentukan rambut jahe instan.

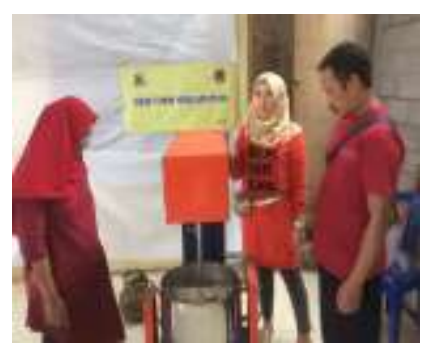

Gambar 3. Penyeraan alat/mesin pengekstrak

Keunggulan dari alat pembuat jamu jahe instan ini adalah 1) waktu pengekstrak relatif singkat yaitu 3040 menit untuk kapasitas 20-25 liter. 2) tidak perlu lagi proses pengadukan yang cukup lama sampai 2 jam.

3) Kapasitas isi besar 4) tidak menggunakan wajan sehingga tidak tumpah 5) Hanya membutuhkan bahan bakar lebih sedikit. Sedangkan kelemahan dari mesin pembuat jamu instan ini : tidak bisa mengolah dengan bahan baku jahe / jamu yang sedikit. Minimal 1x adonan adalah 20 liter $^{4}$.

\section{KESIMPULAN}

Kesimpulan dalam kegiatan ini adalah 1) Pelatihan Pembuatan label dan blog untuk peserta UKM dan pengurus Karangtaruna Bhakti sudah dilaksanakan 2) Pelatihan Kewirausahaan khusus untuk pengurus Krangtaruna Bhakti dan Anggotanya yang sudah dilaksanakan 3) Rencana dan pelaksanaan kegiatan PKM ini berjalan dengan baik dan tanpa halangan yang berarti. Dengan kerjasama tim pengabdian yang baik dan peran serta aktif dari penyuluh/narasumber dalam kegiatan pengabdian ini maka semuanya telah berjalan sesuai yang diharapkan dan harapannya dapat memberikan manfaat bagi mitra pengabdian masyarakat dalam keberlanjutan usaha pada kedua mitra. 4) Mesin jamu instan pada saat ini sudah diserahterimakan. Adapun target dalam program PKM ini sudah sangat sesuai dan tepat, manakala kebutuhan persoalan yang dihadapi mitra 1 dan mitra 2 sangat terakomodasi dengan Tim PKM. Hal ini disadarkan juga oleh metode pelaksanaan kegiatan yang dijalankan dalam porggram ini yaitu, sosialisasi ,Penyuluhan, pelatihan dan pendampingan pada mitra.

Saran dalam kegiatan ini adalah khusus karang taruna Bhakti, perlu adanya pelatihan dan motivasi yang kontinyu, karena keaktifan untuk berwirausaha dan mengangkat ekonomi lokal dalam berusaha masih perlu ditingkatkan.Untuk UKM jamu, selain mesin jamu instan yang diberikan perlu lebih memahami dan membaca situasi pasar tentang jamu jenis apa yang digemari oleh pasar sehingga barang yang dihasilkan akan cepat terjual atau pesanan akan meningkat

\section{VII.DAMPAK DAN MANFAAT KEGIATAN}

Dampak dan Manfaat yang diperoleh mitra dari pelaksanaan kegiatan pokok tersebut bagi UKM Prayogo a). Dapat meningkatkan kuantitas produk minuman saritoga dengan waktu yang lebih singkat, b). Kualitas Produk minuman saritoga lebih terjaga, karena dengan penggunaan teknologi tepat guna didapatkan hasil produk yang lebih bersih dengan ukuran bubuk/butiran yang sama, c) Meningkatnya skill sumberdaya manusia dalam penguasaan serta penggunaan teknologi untuk mempercepat proses produksi, d) Memiliki varian produk baru (yang sempat tidak diproduksi lagi), e) Dapat membuat desain label produk yang tepat dan benar, f) Memiliki web blog untuk promosi produk. Sedangkan untuk Karang Taruna "Bhakti” a) Dapat mengawali kegiatan wirausaha dengan membuat produk baru, b) Dapat 
memotivasi anggota lain untuk berwirausaha sekaligus meingkatkan skill, c) Memiliki pengetahuan \& skill memproduksi minuman jamu.

Target dari Program PKM ini akan tercipta kerjasama yang positif antara UKM Prayogo dengan kelompok Karang Taruna "Bhakti"dalam pengembangan Ilmu dengan UKM Prayogo sebagai pelaku UKM dalam meningkatkan kapasitas produksi dan menyiapkan kader muda yang terampil serta dapat mengembangkan pelatihan yang berkelanjutan bagi Karang Taruna "Bhakti” yang sejalan dengan Program Pemerintah dalam rangka pemberdayaan Pemuda Karang Taruna Dusun Lopawon.

\section{DAFTAR PUSTAKA}

1. Balitbang propinsi Jatim 31 ( Januari - Februari 207) : 22-25 issn 1412-8829.

2. Stepanus."Faktor-Faktor yang Mempengaruhi Pengembangan Tanaman Obat Keluarga di Desa pulau Sapi Kecamatan Mentarang kabupaten Malinau."2011.

http://kumpulanbungamawarku.blogsp ot.com wordpress.com.

3. Tambunan, Tulus, T.H. "Usaha Kecil dan Menengah di Indonesia Beberapa Isu Penting”. Jakarta :PT Salemba Empat. 2002
4. Setyawati, N, Fajarningsih, R U dan KuntoAdi. ."Analisis Potensi Dan Strategi Pengembangan Jamu Instan Di Kabupaten Karanganyar”.2015. https://www.google.co.id/?gws_rd=cr\&ei=zrfPVu ihF9XluQSAjL_wCg\#q=peningkatan+nilai+tamb ah+produksi+ja mu+instant

5. Purwaningsih, E.H.”Jamu, Obat Tradisional Asli Indonesia Pasang Surut Pemanfaatannya di Indonesia”. Jamu Obat Tradisonal, 1(2), (2013):85-89

\section{PENGHARgAaN}

Ucapan terimakasih tim Prgoram PKM pada beberapa pihak antara lain :

1. Kementerian Ristekdikti yang telah memberikan kesempatan kepada pengabdi untuk mengaplikasikan ide pengembangan usaha jamu instan dan pelatian motivasi kewirausaan keada karang taruna Bakti Gn. Kawi Kab Malang.

2. Kepala Desa Kebobang

3. LP3M STIE Asia yang senentiasa support dengan kegiatan pengabdian

4. UKM Saritoga Kebobang dan Karangtaruna Bhakti Gn Kawi Kab. Malang 